\title{
Análise genética de características ponderais e reprodutivas de fêmeas bovinas Tabapuã
}

[Genetics analysis of growth and reproduction traits in a herd of Tabapuã females]

\author{
J.C.C. Pereira ${ }^{1,4}$, S.H.A. Ribeiro ${ }^{2}$, M.A. Silva ${ }^{1,4}$, J.A.G. Bergmann ${ }^{1,4}$, M.D. Costa ${ }^{3}$ \\ ${ }^{1}$ Departamento de Zootecnia da Escola de Veterinária da UFMG \\ Caixa Postal 567 \\ 30123-970 - Belo Horizonte, MG \\ ${ }^{2}$ Doutorando em Ciência Animal - Escola de Veterinária da UFMG \\ ${ }^{3}$ UNIMONTES - Campus Salinas - Salinas, MG \\ ${ }^{4}$ Bolsista do $\mathrm{CNPq}$
}

\begin{abstract}
RESUMO
Foram estudadas 1251 informações referentes aos pesos às idades-padrão de 205 (P205), 365 (P365) e 550 (P550) dias e idade ao primeiro parto (IPP) e primeiro intervalo de partos (IEP1) de fêmeas bovinas da raça Tabapuã. As médias, desvios-padrão e coeficientes de variação foram respectivamente: P205 $173,9 \mathrm{~kg}, 16,0 \mathrm{~kg}$ e $9,2 \%$; P365 - 225,7kg, 28,7kg e 12,7\%; P550-277,0kg, 36,7kg e 13,3\%; IPP - 1125,5 dias, 106,6 dias e 9,5\% e IEP1 - 522,2 dias, 106,2 dias e 20,7\%. As estimativas de componentes de (co)variância e de parâmetros genéticos foram obtidas pelo método de máxima verossimilhança restrita, utilizando-se o software MTDFREML. Para cada característica as estimativas de herdabilidade foram de $0,16,0,25,0,29,0,03$ e 0,01, na mesma ordem de citação acima. As correlações genéticas entre as características ponderais e reprodutivas foram: -0,67 (P205×IPP); -0,07 (P365×IPP); -0,41 (P550×IPP); 0,19 (P205×IEP1); 0,79 (P365×IEP1) e 0,64 (P550×IEP1).
\end{abstract}

Palavras-chave: bovino, Tabapuã, fertilidade, peso

\begin{abstract}
Records on weaning, yearling and 550-day weights, age at first calving and first calving interval from 1251 Tabapuã females, born between 1987 and 1999, were used to estimate variance components and genetic parameters. Statistical analyses were performed and components of (co)variance and genetic parameters were estimated by the derivative-free algorithm based on an animal model. The heritability estimates for weaning, 365 and 550 day weights, age at first calving and first calving interval were: 0.16, $0.25,0.29,0.03$ and 0.01 , respectively. The genetic correlations between weight at those ages and age at first calving were: -0,67; -0,07; -0,41, respectively, and between weights (at weaning, 365 and 550 days) and first calving interval were: $0.19,0.79$ and 0.54, respectively. These results showed a genetic antagonism between weight at different ages with first calving interval, but not with age at first calving.
\end{abstract}

Keywords: cattle, Tabapuã, fertility, weight

Recebido para publicação em 15 de junho de 2004

Recebido para publicação, após modificações, em 29 de outubro de 2004

E-mail: jonas@vet.ufmg.br 


\section{INTRODUÇÃO}

Estratégias de seleção em bovinos de corte que visem compatibilizar características ponderais e reprodutivas são desejáveis, tanto do ponto de vista genético como do econômico. As valorizações da precocidade sexual, do crescimento e do acabamento constituem o foco principal de atuação de melhoristas de bovinos de corte, empenhados na busca de novas vias genéticas de seleção, capazes de dar competitividade às raças zebuínas em relação às taurinas.

A seleção única para peso pode redundar em maior peso à idade adulta, em decorrência de resposta correlacionada. Reconhece-se que a taxa de ganho de peso, em qualquer estádio de crescimento, é geneticamente determinada e associada ao tamanho adulto. Assim, o aumento do tamanho adulto resulta em aumento das exigências de mantença que, se não atendidas, acabam penalizando a idade à puberdade e outras características dela decorrentes (Fitzhugh, 1976; Oliveira et al., 1994).

A compatibilização genética entre os eventos fisiológicos de crescimento e os de reprodução é tarefa complexa, cujos achados são, comumente, contraditórios e até paradoxais. Limitando-se apenas à literatura científica nacional, percebe-se que os resultados de estimativas genéticas de associação entre características ponderais e de fertilidade são contraditórios e, por vezes, dificultam tirar conclusões definitivas a respeito do assunto. Mariante (1985), na raça Nelore, encontrou correlações genéticas positivas entre os pesos ao nascer, aos 12, 18 e 24 meses de idade e a idade ao primeiro parto, de $0,65,0,42$, $0,27,0,21$ e 0,12 , respectivamente. $\mathrm{O}$ autor sugeriu que os genes responsáveis pela promoção de maiores pesos seriam também responsáveis por concepções mais tardias. Mercadante (1995), também com a raça Nelore, mencionou correlações genéticas favoráveis entre os pesos aos 240 e 365 dias e a idade à primeira parição $(-0,10$ e $-0,16$, respectivamente), mas desfavorável $(-0,16)$ entre essas características de crescimento com a eficiência reprodutiva. $\mathrm{O}$ autor sugeriu a existência de antagonismo genético entre eventos fisiológicos de crescimento e reprodução. Ao vincularem pesos às várias idades (ao nascer, à desmama e aos 12, 18 e 24 meses de idade) com a duração de intervalos de partos, Mariante e Zancaner (1985) relataram correlações genéticas de $0,77,0,81$, $0,60,0,37$ e 0,37 , nessa ordem. Sugeriram que o aumento do potencial genético para peso estaria associado a interpartos mais longos.

$\mathrm{Na}$ raça Canchim, pesquisas conduzidas por Barbosa (1991) e Mascioli et al. (1999) registraram semelhante antagonismo genético entre pesos às várias idades e características reprodutivas. Barbosa (1991) encontrou correlações genéticas positivas entre pesos ao nascimento e aos 205 dias de idade e idade ao primeiro parto de 0,47 e 0,37 , respectivamente. Mascioli et al. (1999) relataram $-0,32$ para a correlação genética entre o peso aos 12 meses de idade e a idade ao primeiro parto.

Este estudo teve o objetivo de estimar as correlações genéticas entre características de crescimento e de reprodução de fêmeas bovinas Tabapuã.

\section{MATERIAL E MÉTODOS}

Os dados foram extraídos dos registros zootécnicos da Fazenda Água Milagrosa, no município de Tabapuã, São Paulo. As principais gramíneas utilizadas para o pastejo dos animais são constituídas de Andropogon gayanus, Brachiaria decumbens, Brachiaria humdicola, Brachiaria brizantha cv M, Panicum maximum cv T, Panicum maximum cv C. A mineralização dos animais é feita com cochos distribuídos em todas as divisões, e o regime de criação é extensivo. A suplementação mineral é feita em cochos distribuídos em todos os piquetes das pastagens.

Adota-se a estação de monta, cuja duração se estende de $1^{\circ}$ de outubro até 15 de abril. A relação touro:vaca é de 1:40. As novilhas são acasaladas, ou inseminadas, quando atingem média de peso de $310 \mathrm{~kg}$, com idade variável de 20 a 27 meses.

A fazenda dispõe de instalações constituídas de quatro currais, equipados com balança e brete, pastagens divididas por cercas elétricas e piquetes de tamanho médio de 5,5ha, utilizados para o pastejo rotacionado. Todo o rebanho participa de várias provas zootécnicas oficializadas pela Associação Brasileira de 
Criadores de Zebu (ABCZ), e os registros ponderais são feitos rotineiramente atendendo às normas padronizadas pela referida associação.

Utilizou-se do pacote estatístico Statistical Analysis System (User's..., 1998) para formação de arquivos, consistência e análise descritiva dos dados. Para a consistência dos dados, adotaramse, arbitrariamente, os seguintes limites mínimo e máximo, nesta ordem, para as características pesos ajustados à desmama (205 dias), aos 365 dias e 550 dias de idade, idade ao primeiro parto e intervalo de partos: $120 \mathrm{~kg}$ e $300 \mathrm{~kg} ; 150 \mathrm{~kg}$ e $300 \mathrm{~kg}$; $200 \mathrm{~kg}$ e $500 \mathrm{~kg}$; 730 dias e 1825 dias; e 290 dias e 770 dias.

Os componentes de (co)variância para cálculo dos correspondentes parâmetros genéticos foram estimados pelo método da máxima verossimilhança restrita livre de derivadas sob modelo animal (MTDFREML), desenvolvido por Boldman et al. (1995). Em todas as características estudadas, foram considerados os efeitos fixos de ano e mês de nascimento para as características ponderais e ano e mês de parição para as de reprodução, agrupadas sob forma de grupos de contemporâneos.

\section{RESULTADOS E DISCUSSÃO}

Os resultados referentes a 1251 dados de pesos às idades-padrão de 205 (P205), 365 (P365), 550 (P550) dias foram, respectivamente: $173,9 \pm 16,0 \mathrm{~kg}$ e $9,2 \% ; 225,7 \pm 28,7 \mathrm{~kg}$ e $12,7 \%$ e $277,0 \pm 36,7 \mathrm{~kg}$ e $13,3 \%$. Para idades à primeira parição (IPP) e primeiro intervalo de partos (IEP1), na mesma ordem, foram: $1125,5 \pm 106,6$ dias e $9,5 \%$ e $522,2 \pm 106,2$ dias e $20,7 \%$.

As análises com característica única resultaram em estimativas dos componentes de variância e parâmetros genéticos das características ponderais e reprodutivas apresentadas na Tab. 1.

As estimativas de herdabilidades das características ponderais avaliadas aos 205 e 365 dias de idade, 0,16 e 0,25, aproximam-se das relatadas por Borjas et al. (1994) e Magnabosco et al. (1995). No entanto, valores mais elevados de herdabilidades para essas mesmas características foram relatados por Dias (2001) e Gressler et al. (2005). Em revisão feita por Mercadante (1995), limitada apenas a bovinos
Zebus, a autora encontrou, para peso a um ano de idade, média de herdabilidade de 0,24 $\pm 0,02$. É comentário consensual entre os melhoristas que as características ponderais oferecem apreciável variação genética e que resultados favoráveis podem ser obtidos pela seleção massal para as mesmas.

Tabela 1. Estimativas de componentes de variância e parâmetros genéticos dos pesos aos 205 (P205), 365 (P365), 550 (P550) dias de idade e idade ao primeiro parto (IPP) e primeiro intervalo de partos (IEP1), em dias, obtidas mediante análise de cada caráter, de fêmeas bovinas da raça Tabapuã

\begin{tabular}{lcccc}
\hline Característica & $\sigma_{\mathrm{a}}^{2}$ & $\sigma_{\mathrm{e}}^{2}$ & $\sigma_{\mathrm{p}}^{2}$ & $\mathrm{~h}^{2}$ \\
\hline P205 & 33,60 & 173,05 & 206,65 & 0,16 \\
P365 & 131,95 & 399,71 & 531,66 & 0,25 \\
P550 & 290,91 & 713,64 & 1004,55 & 0,29 \\
IPP & 176,58 & 5317,20 & 5493,78 & 0,03 \\
IEP1 & 67,18 & 8579,59 & 8646,77 & 0,01 \\
\hline
\end{tabular}

As estimativas de herdabilidade apresentaram valores próximos de zero, indicando a inexistência de variabilidade genética, tanto para idade ao primeiro parto como para o primeiro intervalo de partos. Reconhece-se na literatura científica que a maioria dos eventos fisiológicos, comumente incluídos na fertilidade das fêmeas, apresentam valores baixos de herdabilidade. A idade ao primeiro parto, por estar geneticamente vinculada ao peso à puberdade, parece constituir exceção a essa regra. Koots et al. (1994), ao revisarem estimativas de parâmetros genéticos de característica de importância econômica em gado de corte, mencionaram valores não-ponderados e ponderados (pelo inverso do quadrado do erropadrão de cada estimativa) de herdabilidade da IPP em $0,14 \pm 0,18$ e $0,06 \pm 0,02$, respectivamente. É razoável justificar o baixo valor aos seguintes argumentos: a) os dados utilizados no estudo provêm de rebanho formador de raça, o qual vem sendo selecionado para reprodução de longa data; assim, é razoável admitir que a variação genética para a IPP tenha sido reduzida na esteira do tempo; b) a existência da endogamia nos animais presentes no estudo de apenas 4\% poderia contribuir para a redução da variação genética aditiva da característica em foco. A inclusão da endogamia como covariável não provocou alteração na estimativa da herdabilidade, o que rechaça essa hipótese. 


\section{Pereira et al.}

Aceita-se o valor encontrado, nos dados analisados, como compatível com a realidade genética da característica no rebanho.

Em relação ao IEPI, a estimativa de herdabilidade encontrada, 0,01, pode ser considerada nula. Esse valor, compatível com a maioria dos relatos disponíveis na literatura científica a respeito, indica que a variável é pouco influenciada por genes de ação aditiva e fortemente dependente de ações genéticas nãoaditivas e de efeitos ambientes. Entre as inúmeras citações disponíveis cujos valores de herdabilidade se aproximam do aqui constatado podem ser mencionadas: Biffani et al. (2000), Pereira et al. (2000) e Gressler et al. (2005), todos na raça Nelore. Relatam ainda valores superiores os seguintes pesquisadores, dentre outros: Mercadante (1995), Gressler (1998) e Simioni (2002).

$\mathrm{Na}$ Tab. 2 são apresentadas as análises bicaracterísticas referentes às características ponderais e de fertilidade.

Tabela 2. Estimativas de componentes de (co)variância e parâmetros genéticos dos pesos aos 205 (P205), 365 (P365), 550 (P550) dias e idade ao primeiro parto (IPP) e primeiro intervalo de partos (IEP1), obtidas mediante análises bivariadas, de fêmeas bovinas da raça Tabapuã

\begin{tabular}{ccccccccccc}
\multicolumn{1}{c}{ Característica } & $\sigma 2_{\mathrm{A} 1}$ & $\sigma_{\mathrm{A} 2}^{2}$ & $\sigma_{\mathrm{A} 1,2}$ & $\sigma_{\mathrm{E} 1}^{2}$ & $\sigma_{\mathrm{E} 2}^{2}$ & $\sigma_{\mathrm{P} 1}^{2}$ & $\sigma_{\mathrm{P} 2}^{2}$ & $\mathrm{~h}_{1}^{2}$ & $\mathrm{~h}_{2}^{2}$ & $\mathrm{r}_{\mathrm{A} 12}$ \\
\hline P205 $\times$ IPP & 33,91 & 144,60 & $-47,11$ & 172,86 & 5347,04 & 206,77 & 5491,64 & 0,16 & 0,03 & $-0,67$ \\
P365 × IPP & 131,82 & 173,09 & $-11,09$ & 399,63 & 5320,56 & 531,44 & 5493,64 & 0,25 & 0,03 & $-0,07$ \\
P550 $\times$ IPP & 296,27 & 115,09 & $-75,09$ & 708,95 & 5377,84 & 1005,22 & 5492,93 & 0,29 & 0,02 & $-0,41$ \\
P205 $\times$ IEP1 & 33,83 & 67,30 & 9,24 & 172,88 & 8580,07 & 206,71 & 8647,37 & 0,16 & 0,01 & 0,19 \\
P365 $\times$ IPE1 & 139,96 & 180,52 & 126,12 & 392,79 & 8463,68 & 532,75 & 8644,21 & 0,26 & 0,02 & 0,79 \\
P550 $\times$ IPE1 & 297,23 & 87,76 & 103,27 & 708,16 & 8557,37 & 1005,39 & 8645,13 & 0,30 & 0,01 & 0,64 \\
\hline
\end{tabular}

$\sigma 2_{\mathrm{A} 1}=$ variância genética aditiva da característica $1 ; \sigma 2_{\mathrm{A} 2}=$ variância genética aditiva da característica $2 ; \sigma_{\mathrm{A} 1,2}=$ covariância genética aditiva entre as características 1 e $2 ; \sigma_{\mathrm{E} 1}^{2}=$ variância residual da característica $1 ; \sigma_{\mathrm{E} 2}^{2}=$ variância residual da característica 2 ; $\sigma_{P 1}^{2}=$ variância fenotípica da característica $1 ; \sigma_{\mathrm{P} 2}^{2}=$ variância fenotípica da característica $2 ; \mathrm{h}^{2}{ }_{1}=$ herdabilidade da característica 1 ; $\mathrm{h}_{2}^{2}=$ herdabilidade da característica $2 ; \mathrm{r}_{\mathrm{A} 12}=$ correlação genética entre as características 1 e 2 .

De modo geral, vê-se que as estimativas de herdabilidade obtidas nas análises do tipo unicaráter estão perfeitamente compatíveis com as análises do tipo bicaráter. Nessa situação, é razoável recomendar a análise unicaráter para estimativas de componentes de variância e coeficientes de herdabilidade, à semelhança de Dias (2001). Meyer et al. (1990) e Johnston e Bunter (1996) relataram variações nos parâmetros genéticos entre modelos com apenas uma variável e mais de uma variável. Em tais situações, para a obtenção de parâmetros genéticos obtidos de análises uni e bicaráter, é recomendável a inclusão de análises multicaráter em qualquer estudo que visa a predições de valores genéticos dos animais.

As correlações genéticas encontradas entre o peso à desmama, 365 e 550 dias de idade, e a idade ao primeiro parto $(-0,67,-0,07$ e $-0,41$, respectivamente) indicam associação favorável entre essas características ponderais e a idade ao primeiro parto. É razoável afirmar que aquelas fêmeas com maior potencial de crescimento pósdesmama foram mais precoces por ocasião do primeiro parto. Constatações similares foram também mencionadas por Bourdon e Brinks (1982), -0,22, Mercadante (1985) e Garnero et al. (2001), ambas -0,09, Gressler et al. (2005), -0,20, todas vinculando o peso à desmama com a idade ao primeiro parto.

Pode-se afirmar que a precocidade sexual, avaliada pela idade ao primeiro parto, parece estar associada a taxas de crescimento corporal relativo em idades jovens, evidenciando a importância das diferenças entre curvas de crescimento dos animais, argumentos defendidos por Bergmann e Hohenboken (1992). No entanto, há pesquisadores que relatam correlações genéticas positivas entre as características ponderais e a idade ao primeiro parto, como Mariante e Zancaner (1985) e Barbosa (1991), permitindo inferir que esses resultados, paradoxalmente contraditórios, reforçam a necessidade de outros estudos na mesma direção e que possam subsidiar, com mais consistência, recomendação a esse respeito. Tal argumento se aplica à correlação genética encontrada entre o peso aos 365 dias de idade e a 
idade ao primeiro parto $(-0,07)$, valor praticamente zero. Uma interpretação ortodoxa implicaria dizer que as características seriam independentes do ponto de vista genético. São raras as citações em Zebu que tratam das relações genéticas entre essas características. Apenas Mascioli et al. (1999) mencionaram o valor de $-0,32$ para a correlação genética entre P365 e IPP na raça Canchim. Parece não restar dúvida de que há necessidade de multiplicar estudos em raças Zebus visando extrair subsídios genéticos mais consistentes para as relações genéticas entre características ponderais $\mathrm{e}$ aquelas indicadoras de fertilidade.

Quando as mesmas características ponderais (P205, P365 e P550) foram vinculadas geneticamente à duração do primeiro intervalo de partos (IEP1), as correlações foram todas positivas, significando que maiores pesos para essas idades poderiam implicar alongamento da duração do primeiro interparto. É possível encontrar explicação aparentemente plausível para resultado tão surpreendente. $O$ estresse da parição, notadamente nas primíparas, em associação ao provocado pela lactação, poderia atuar inibindo possíveis sinergismos genéticos entre maiores pesos às idades consideradas e duração do primeiro intervalo de partos. $\mathrm{O}$ resultado evidencia que as primíparas deverão merecer manejo nutricional diferenciado como forma de minimizar ou atenuar esse antagonismo genético.

\section{CONCLUSÕES}

As estimativas de herdabilidade obtidas para as características ponderais e as de reprodução, em fêmeas da raça Tabapuã, reforçam a recomendação de que a seleção é capaz de promover progressos genéticos para as primeiras e de que a adoção de práticas de melhoria de natureza ambiental é a mais indicada para o melhoramento das segundas. Relações genéticas favoráveis foram encontradas entre características ponderais e idade ao primeiro parto, caracterizando ação de sinergismo entre genes favoráveis às características ponderais e os ligados à expressão da idade ao primeiro parto. Relações genéticas positivas, mas desfavoráveis em seus efeitos, foram constatadas entre características ponderais e duração do primeiro intervalo de partos, caracterizando possível antagonismo genético entre esses eventos fisiológicos.

\section{AGRADECIMENTOS}

Os autores agradecem ao Dr. Carlos Arthur Ortemblad pela gentileza em ceder os dados e pelo incentivo dispensado ao presente estudo, bem como ao Dr. Paulo Henrique Julião de Camargo, gerente técnico da Fazenda Água Milagrosa, pelas informações técnicas.

\section{REFERÊNCIAS BIBLIOGRÁFICAS}

BARBOSA, P.F. Análise genético-quantitativa de características de crescimento e reprodução em fêmeas da raça Canchim. 1991. 237f. Tese (Doutorado) - Faculdade de Medicina de Ribeirão Preto, Universidade de São Paulo, Ribeirão Preto, SP.

BERGMANN, J.A.G.; HOHENBOKEN, W.D. Prediction of fertility from calfhood traits of Angus and Simmental heifers. J. Anim. Sci., v.70, p.2611-2621, 1992.

BIFFANI, S.; MATINS F.R.; LUCIFERO, M. et al. Características reprodutivas de fêmeas da raça Nelore criadas na região Nordeste do Brasil. In: REUNIÃO ANUAL DA SOCIEDADE BRASILEIRA DE ZOOTECNIA, 37., 2000, Viçosa. Anais... Viçosa: SBZ, 2000. p.202.

BOLDMAN, K.G.; KRIESE, L.A.; VAN VLECK, L.D. et al. A manual for use of MTDFREML: a set of programs to obtain estimates of variances and covariances (DRAFT). Lincoln Department of Agriculture / Agricultural Research Service, 1995. 125p.

BORJAS, A.R.; LÔBO, R.B.; OLIVEIRA, H.N. et al. Estimativas de efeitos genéticos direto e maternal para pesos até 365 dias usando modelo animal bivariado em rebanhos Nelore. In: REUNIÃO ANUAL DA SOCIEDADE BRASILEIRA DE ZOOTECNIA, 31., 1994, Maringá. Anais... Maringá: SBZ, 1994. p.167.

BOURDON, R.M.; BRINKS, J.S. Genetic, environmental and phenotypic relationships among gestation length, birth weight, growth traits and age at first calving in beef cattle. $J$. Anim. Sci., v.55, p.543-553, 1982. 
DIAS, D.S.O. Análise genética de características de crescimento e de reprodução de animais da raça Nelore criados na região Centro-Oeste do Brasil. 2001. 117f. Tese (Doutorado) Faculdade de Ciências Agrárias e Veterinárias, Universidade Estadual Paulista, Jaboticabal, SP.

FITZHUGH, H.A. Analysis of growth curves and strategies for altering their shape. J. Anim. Sci., v.42, p.1036,1051, 1976.

GARNERO, A.V.; LÔBO, R.B.; BEZERRA, L.A.F. et al. Comparação entre alguns critérios de seleção para crescimento na raça Nelore. Rev. Bras. Zootec., v.30, p.714-718, 2001.

GRESSLER, M.G.M.; PEREIRA, J.C.C.; BERGMANN, J.A.G. et al. Aspectos genéticos do peso à desmama e de algumas características reprodutivas de fêmeas Nelore. Arq. Bras. Med. Vet. Zootec., v.57, p.533-538, 2005

GRESSLER, S.L. Estudo de fatores de ambiente e parâmetros genéticos de algumas características reprodutivas em animais da raça Nelore. 1998. 149f. Dissertação (Mestrado) Escola de Veterinária, Universidade Federal de Minas Gerais, Belo Horizonte.

JOHNSTON, D.J.; BUNTER, K.L. Days to calving in Angus cattle: genetics and environmental effects and covariances with other traits. Liv. Prod. Sci., v.45, p.13-22, 1996.

KOOTS, K.R.; GIBSON, J.P.; SMITH, C. et al. Analysis of published genetic parameter estimates for beef production traits. 1. Heritability. Anim. Breed. Abst., v.62, p.309-338, 1994.

MAGNABOSCO, C.U.; FAMULA, T.R.; LÔBO, R.B. et al. Componentes de variância e covariância para características de crescimento em rebanho da raça Nelore Mocho. In: REUNIÃO ANUAL DA SOCIEDADE BRASILEIRA DE ZOOTECNIA, 32., 1995, Brasília. Anais... Brasília, SBZ, 1995. p.677, 678.

MARIANTE, A.S. Growth and reproduction in Nelore cattle in Brazil: genetic parameters and effects of environmental factors. 1978. 131f. Thesis (PhD) - University of Florida, Gainesville, Florida.
MARIANTE, A.S.; ZANCANER. A. Crescimento e reprodução em gado Nelore: visão do criador e do pesquisador. São Paulo: Criadores, $1985.152 \mathrm{p}$.

MASCIOLI, A.S.; TALHARI, F.M.; ALENCAR, M.M. et al. Correlações genéticas entre características reprodutivas e de crescimento de fêmeas da raça Canchim. In: REUNIÃO ANUAL DA SOCIEDADE BRASILEIRA DE ZOOTECNIA, 36., 2000, Porto Alegre. Anais... Porto Alegre: SBZ, 1999. p.156.

MERCADANTE, M.E.Z. Estudo das relações genético-quantitativas entre características de reprodução, crescimento e produção em fêmeas da raça Nelore. 1995. 90f. Dissertação (Mestrado) - Faculdade de Medicina de Ribeirão Preto, Universidade de São Paulo, Ribeirão Preto, SP.

MEYER, K.; HAMMOND, K.; PARNELL, P.F. et al. Estimates of heritability and repeatability for reproductive traits in Australian beef cattle. Liv. Prod. Sci., v.25, p.15-30, 1990.

OLIVEIRA, H.N.; LÔBO, R.B.; PEREIRA, C.S. Relationship among growth curve parameters, weights and reproductive traits in Guzera beef cows. In: WORLD CONGRESS ON GENETICS APPLIED TO LIVESTOCK PRODUCTION, 5., 1994, Guelph. Proceedings... Guelph, 1994. p.19.

PEREIRA, E.; ELER, J.P.; FERRAZ, J.B.S. et al. Análise genética do intervalo de partos e primeiro intervalo de partos na raça Nelore. In: SIMPÓSIO NACIONAL DA SOCIEDADE BRASILEIRA DE MELHORAMENTO ANIMAL, 3., 2000, Belo Horizonte. Anais... Belo Horizonte: SBMA, 2000. p.433-434.

SIMIONI, V.M. Estudo genético-quantitativo de algumas características reprodutivas na raça Nelore. 2002. 40f. Tese (Doutorado) - Faculdade de Ciências Agrárias e Veterinárias de Jaboticabal, Universidade Estadual Paulista, Jaboticabal, SP.

USER'S guide: statistics. Cary, NC: SAS Institute, 1998. 